\title{
A SHECA TUBE STUDY OF THE REACTIONS OF THE HYDROXYL RADICAL WTTH COMBUSTION SPECIES AND POLLUTANTS
}

\author{
N. Cohen \\ Space and Environment Technology Center \\ The Aerospace Corporation \\ P. O. Box 92957 \\ Los Angeles, CA 90009-2957
}

$\mathrm{DOE} / \mathrm{ER} / 13812--\mathrm{T} 2$

DE93 013181

\author{
Progress Report
}

August 1992

Submitted to

Dr. Allan H. Laufer

Division of Chemical Sciences

Office Of Basic Energy Sciences

Department of Energy

\section{DISCLAIMER}

This report was prepared as an account of work sponsored by an agency of the United States Government. Neither the United States Government nor any agency thereof, nor any of their employees, makes any warranty, express or implied, or assumes any legal liability or responsibility for the accuracy, completeness, or usefulness of any information, apparatus, product, or process disclosed, or represents that its use would not infringe privately owned rights. Reference herein to any specific commercial product, process, or service by trade name, trademark, manufacturer, or otherwise does not necessarily constitute or imply its endorsement, recommendation, or favoring by the United States Government or any agency thereof. The views and opinions of authors expressed herein do not necessarily state or reflect those of the United States Government or any agency thereof. 


\section{i. INTRODUCTION}

The reactions of $\mathrm{OH}$ radicals with hydrocarbons have received a great deal of attention in recent years because of these processes are principal steps in the oxidation of organic fuels--whether occuring in combustion/propulsion systems, in the atmosphere, or elsewhere. Of the various radicals capable of attacking hydrocarbons, $\mathrm{OH}$ radicals are generally the most reactive. In the atmosphere, the combined effects of the $\mathrm{OH}$ radical's reactivity and concentration make it the single species that determines the atmospheric lifetime of an organic substance. In many combustion systems, the $\mathrm{OH}$ radical plays a similar rate-determining role in the kinetics of fuel oxidation.

The principal goals of the kineticist in the field of oxidation chemistry are (1) to measure as many elementary reaction rate coefficients as are conveniently studied in the laboratory; and (2) to develop theoreti$\mathrm{cal}$ and/or semiempirical tools for extrapolating from measured rate coefficients to unmeasured ones. The latter step is necessary because of the sheer number of reactions of possible interest. Ab initio theoretical studies provide the most refined nonexperimental procedures for the completion of part (2) of the above program, but again, the large number of reactions (and the considerable cost of computer time) renders impractical detailed theoretical evaluation of every one. To this end, Benson and coworkers ${ }^{1}$ developed the procedures of the thermochemical kinetics (TK) approach to transition state theory (TST): a collection of recipes and simple techniques for predicting reaction rate coefficients with reasonable accuracy. The method is most reliable when used simply to extrapolate rate coefficients from one temperature range to other temperatures, but a single temperature measurement can provide the basis for extrapolation. The procedure is further sharpened when applied to a family of homologous reactions for which a set of experimental measurements places more stringent constraints on the structural parameters of the activated complex that are required for the calculations. (It is assumed that the activated complexes for a homologous series of reactions are very similar to one another.) Studies of $\mathrm{OH}$ radicals with a series of alkanes have provided a wealth of experimental data that constitute an ideal test case for the application of thermochemical kinetics to predicting reaction rate coefficients.

To extend the semi-empirical techniques of Benson and coworkers, and to extend the database of reliable high temperature measurements of $\mathrm{OH}$ radicals with hydrocarbons and other fuels and their decomposition products, we undertook, with DOE support, a research program with both experimental and computational tasks. The experimental goal was to design a procedure for measuring, at combustion temperatures, the reaction rate coefficients of $\mathrm{OH}$ radicals with fuels and other species of importance in combustion or propulsion systems. The computational effort was intended to refine the semi-empirical thermochemical kinetics/transition-state-theory (TK-TST) procedures for extrapolating rate coefficients of reactions of OH with combustion species of interest, for predicting rate coefficients for species not studied in the laboratory, and to examine the ability of the theory to predict rate coefficients for different pathways in cases where the reagent possessed nonequivalent $\mathrm{H}$ atoms. 


\section{PROCEDURE}

The experiments are performed in our shock tube facility. The stainless steel shock tube has a $10-\mathrm{m}$ long, 16.2-cm-diam test section with a 3-m-long, $7.5-\mathrm{cm}$-diam driver section. The shock tube, the gas-handling equipment, and the optical configuration were described in detail in Ref. 6.

A schematic drawing of the apparatus is shown in Fig. 1.

The fast-opening diaphragm section and large vacuum pumps permit a large number of runs each day. $t$-butyl hydroperoxide (TBH) dissociates rapidly at our temperatures (near $1200 \mathrm{~K}$ ) to produce t-butoxy and $\mathrm{OH}$ radicals:

$$
\left(\mathrm{CH}_{3}\right)_{3} \mathrm{COOH} \rightarrow\left(\mathrm{CH}_{3}\right)_{3} \mathrm{CO}+\mathrm{OH} \quad \mathrm{k}_{\mathrm{a}}=6.6 \times 10^{7} \mathrm{sec}^{-1}
$$

the t-butoxy radicals in turn very rapidly dissociate to give $\mathrm{CH}_{3}$ radicals and acetone:

$$
\left(\mathrm{CH}_{3}\right)_{3} \mathrm{CO} \ldots \mathrm{CH}_{3}+\mathrm{CH}_{3} \mathrm{COCH}_{3} . \quad \mathrm{k}_{\mathrm{b}}=\mathrm{ca} .3 \times 10^{10} \mathrm{sec}^{-1}
$$

The acetone then decomposes--but, unfortunately, not very fast on our time scale--to give $\mathrm{CH}_{3}$ and $\cdot \mathrm{CH}_{3} \mathrm{CO}$ radicals:

$$
\mathrm{CH}_{3} \mathrm{COCH}_{3}->\mathrm{CH}_{3} \mathrm{CO}+\mathrm{CH}_{3} \quad \mathrm{k}_{\mathrm{c}}=40 \mathrm{sec}^{-1}
$$

And the $\mathrm{CH}_{3} \mathrm{CO}$ radicals will rapidly fall apart to give $\mathrm{CH}_{3}$ and $\mathrm{CO}$ :

$$
\mathrm{CH}_{3} \mathrm{CO} \ldots \mathrm{CH}_{3}+\mathrm{CO} \quad \mathrm{k}_{\mathrm{d}}=c a .4 \times 10^{10} \mathrm{sec}^{-1}
$$

The net result of these four reactions is:

$$
\left(\mathrm{CH}_{3}\right)_{3} \mathrm{COOH}->\cdot \mathrm{OH}+3 \cdot \mathrm{CH}_{3}+\mathrm{CO}
$$

If the third reaction were sufficiently fast, then the analysis of the measurements would be considerably simplified, because we would then be looking at an instantaneously produced concentration of $\mathrm{OH}$ radicals, $\mathrm{CH}_{3}$ radicals, and $\mathrm{CO}$. The fact that this is not so forces us to model $[\mathrm{OH}]$ as a function of time and deduce reaction rates of the $\mathrm{OH}$ with added substrates by computer modeling.

Thin-film heat transfer gauges mounted in the tube wall signal the passage of the shock wave. The speed of the shock wave is calculated from the distance between the gauges and the time between the heat transfer gauge signals. From the shock speed and initial conditions, the pressure and temperature behind the reflected shock are calculated.

The $\mathrm{OH}$ radical then undergo several reactions in the absence of any other reagents, and have a characteristic half-life. When another reagent is present, it too can react with the $\mathrm{OH}$. From the disappearance rate of $\mathrm{OH}$ as a function of the added reagent $\mathrm{RH}$ concentration, the reaction rate coefficient for the process, $\mathrm{OH}+$ $\mathrm{RH}$-.> products, is calculated. The $\mathrm{OH}$ concentration behind the shock wave was monitored by uv absorption using $\mathrm{OH}$ resonance radiation at $309 \mathrm{~nm}$, produced by a microwave discharge through a mixture of helium and water vapor flowing at 70 torr.

Gas mixtures containing a concentration of $40 \mathrm{ppm}$ of TBH are used. They are prepared by injecting the reagent substrate to be studied into a Teflon-coated mix tank containing 1.2 torr of TBH. The resulting mixture is diluted with argon through a supersonic injection sting to insure rapid, thorough mixing. A franction of the mixture is diluted further to the requried concentration. The gases include TBH (with impurities of $5 \%$ t-butyl alcohol and 5\% water) and argon (Matheson UHP, 99.999\%). 
The operating procedure is to fill the evacuated shock tube with the test gas to a pressure of typically 50 torr. The test gas is then flowed through the tube and exhausted through the end wall until about 25 to $30 \%$ of the gas has been replaced. This flushes out impurities pushed toward the end wall during the fill. Fresh gas replaces the slug of test gas at the end of the tube, from which some of the TBH hay have been lost to the wall. This procedure was also used with success in earlier studies of HF vibrational relaxation ${ }^{2}$ in which the results depended directly on the HF concentration. Reproducible levels of absorption are obtained with this procedure, and no absorption is measured without the TBH in the gas mixture.

The experiments are performed behind the reflected shock wave with $[\mathrm{OH}]$ being monitored by means of uv absorption measurements. The $\mathrm{OH}$ resonance radiation in the (A - X) system is obtained from a microwave-powered discuarge through a mixture of helium and water vapor flowing at 70 torr through $12 \mathrm{~mm}$ external-diam quartz tubing fitted with a quartz window. Flow rates of dry helium and wet helium are adjusted to maximize the output intensity. The high intensity and stability of the lamp enable us to measure decay rates of $\mathrm{OH}$ at initial concentrations of $5 \times 10^{-10} \mathrm{~mol} \mathrm{~cm}^{-3}$ (with a nominal $40 \mathrm{ppm} \mathrm{TBH}$ at $1200 \mathrm{~K}$ and $1.25 \mathrm{~atm}$ ), for which the absorption is $12 \%$ in the present single-pass optical system.

The emission from the discharge is focused with $5-\mathrm{cm}-$ diam, $15-\mathrm{cm}$-focal-length quartz lenses at the center of the shock tube and then onto the entrance slit of a Bausch and Lomb monochromator. With a 1.34$\mathrm{mm}$ entrance slit and $0.75-\mathrm{mm}$ exit slit combination, the monochromator has a bandpass of $4.8 \mathrm{~nm}$ at $309 \mathrm{~nm}$. The photomultiplier (RCA 1P28) mounted at the exit slit of the monochromator has a time response of 2 usec with a $2 \mathrm{kOhm}$ load resistor. The photomultiplier signal for each run is recorded with a Biomation 805 transient recorder, stored in a Nicolet 1072 signal averager, and then transferred to a DEC PDP 11/23 computer for data reduction. An exponential decay time is determined for the data of each run.

The $\mathrm{OH}$ concentration can be related to its uv absorption. However, because of the large spectral band width $(4.8 \mathrm{~nm})$ of the detected emission, the $\mathrm{OH}$ absorption is not expected to oicy Beer-Lambert's law, but can be described approximately by

$$
\ln \left(\mathrm{I}_{\mathrm{o}} / \mathrm{I}\right)=e_{\mathrm{eff}}([\mathrm{OH}] \times \mathrm{x} l)^{\mathrm{v}}
$$

where $\mathrm{I}$ is the light signal seen by a detector, $l=$ optical path length and $e_{\text {eff }}=$ effective extinction coefficient. $e_{\text {eff }}$ and $v$ are functions of the gas temperature and pressure, the slit width, and the operating characteristics of the lamp. The problem of calibrating $\mathrm{OH}$ emission sources for the detection of $\mathrm{OH}$ has been described by Schott and Getzinger. ${ }^{3}$ It has proven practical to calibrate detection systems by shock-heating mixtures of $\mathrm{H}_{2}$, $\mathrm{O}_{2}$, and argon and measuring the absorption by $\mathrm{OH}$, the concentration of which can be calculated for the partially equilibrated gas mixture. $.^{3,4}, 5$ With our lamp, a value of 0.91 for $v$ was obtained. ${ }^{6}$ Because the OH absorption occurs on lines having lower rotational state quantum numbers in the range of 1 to 10 , there is only a minor effect of temperature on the absorption coefficient in the $1000-3000 \mathrm{~K}$ range ${ }^{3,4}$ Bradley et al. ${ }^{5}$ found $v=0.58$, while Ernst, Wagner, and Zellner ${ }^{4}$ found $v=0.74$ for temperatures between 1200 and $2000 \mathrm{~K}$. Our lamp is similar to that of Ernst et al., except that they used argon instead of helium as the carrier gas and operated at 1 torr instead of 70 torr. Details of our calibration procedure are given in Ref. 6. 
If $\mathrm{OH}$ is removed by reaction with reagent $\mathrm{RH}$, the rate law for its disappearance is

$$
d[\mathrm{OH}] / \mathrm{dt}=-\mathrm{k}[\mathrm{OH}][\mathrm{RH}],
$$

or

$$
\ln \left([\mathrm{OH}]_{\mathrm{t}} /[\mathrm{OH}]_{\mathrm{O}}\right)=-\mathrm{k}[\mathrm{RH}] \mathrm{t}
$$

or

$$
[\mathrm{OH}]_{\mathrm{t}} /[\mathrm{OH}]_{\mathrm{O}}=\exp (-\mathrm{k}[\mathrm{RH}] \mathrm{t})
$$

From eq (1),

$$
\ln [\mathrm{OH}]_{\mathrm{t}}=(1 / v) \ln \left[\ln \left(1-\mathrm{I}_{\mathrm{t}} / \mathrm{I}_{\mathrm{i}}\right)\right]-C
$$

where $\mathrm{I}_{\mathrm{i}}$ and $\mathrm{I}_{\mathrm{t}}$ are the transmitted light with no OH present (i.e., the incident beam) and at time $t$ after generation of the $\mathrm{OH}$, respectively; $C$ is a constant that depends on $l, v$, and $e$.

From the last equation,

$$
\ln \left([\mathrm{OH}]_{\mathrm{t}} /[\mathrm{OH}]_{\mathrm{O}}\right)=\left\{\ln \left[\ln \left(\mathrm{I}_{\mathrm{i}} / \mathrm{I}_{\mathrm{t}}\right)\right]-\ln \left[\ln \left(\mathrm{I}_{\mathrm{i}} / \mathrm{I}_{\mathrm{o}}\right)\right]\right\} / v
$$

Hence, it is not necessary to know the absolute $\mathrm{OH}$ concentrations to deduce the rate coefficient for the $\mathrm{OH}+\mathrm{RH}$ reaction; a plot of the right hand side of eq (6) $v s$. t gives $\mathrm{k}[\mathrm{RH}]$. The decay rates are measured for different concentrations of the reagent $\mathrm{RH}$ being studied, and the rate coefficient for OH removal is determined from the slope of the decay rate plotted $v s$. [RH]. However, the calibration data are necessary to confirm that the dependence of the absorption on $[\mathrm{OH}]$ can be described by Eq. 1 and to establish the value of $v$.

For small levels of absorption, it can be shown that the exponential decay rate of $[\mathrm{OH}]$ is approximately equal to the exponential decay rate of the $\mathrm{OH}$ absorption divided by $v$, the absorption parameter of Eq. 1 .

The computed $[\mathrm{OH}]$ profiles in the presence of propane could be described accurately with an exponential removal rate. However, in addition to the reaction of $\mathrm{OH}$ with the propane itself, other chemical reactions remove some $\mathrm{OH}$. These include reactions with $\mathrm{OH}$ itself; with $\mathrm{CH}_{3}, \mathrm{CO}$, and $\mathrm{CH}_{3} \mathrm{COCH}_{3}$, all formed by the decomposition of the TBH; and with $\mathrm{C}_{2} \mathrm{H}_{6}$ and $\mathrm{C}_{2} \mathrm{H}_{4}$, both formed by subsequent reactions of the $\mathrm{CH}_{3}$ radicals. At initial times, the reaction with $\mathrm{CH}_{3}$ is the fastest removal process. In order to determine the relationship of the empirical $\mathrm{OH}$ removal rate to the rate coefficient of the reaction with the principal reagent (in this case, propane), computer calculations were carried out with NEST, a chemical kinetics code, using the experimental conditions of the study. Literature values were used for rate coefficient where possible, and best estimates were used for the others. The calculated exponential decay rates of $[\mathrm{OH}]$ were plotted vs. [RH], and fell along a straight line with a slope within a few percent of the input value for the rate coefficient of the $\mathrm{OH}+$ propane reaction. This result justified the method of deducing the rate coefficient from the slope of the measured decay rates plotted $v s$. RH concentrations. In some of the other cases studied previously, ${ }^{8}$ there was the possibility of the $\mathrm{OH}$ reacting with other decomposition products of the reagent being studied if the latter underwent substantial thermal decomposition. To guard against misinterpretation of the experimental data, computer simulations were carried out wherever appropriate.

Because reaction with $\mathrm{CH}_{3}$ is always occuring in our system, we decided to attempt a direct measurement of this reaction rate. In the procedure outlined above, $\mathrm{CH}_{3}$ is produced via reactions $\mathrm{b}, \mathrm{c}$, and d. Overall, 
three $\mathrm{CH}_{3}$ radicals are produced for every $\mathrm{OH}$ radical in the pyrolysis of the TBH. In order to vary the ratio of $[\mathrm{OH}]:\left[\mathrm{CH}_{3}\right]$, varying quantities of di-t-butyl-peroxide (TBP) were added to the TBH. Like TBH, TBP decomposes rapidly at the temperatures behind the reflected shock tube, but produces only $\mathrm{CH}_{3}$ and $\mathrm{CO}$ :

$$
\begin{aligned}
& \left(\mathrm{CH}_{3}\right)_{3} \mathrm{COOC}\left(\mathrm{CH}_{3}\right)_{3}->2\left(\mathrm{CH}_{3}\right)_{3} \mathrm{CO} \cdot \\
& \left(\mathrm{CH}_{3}\right)_{3} \mathrm{CO} \cdots \mathrm{CH}_{3}+\mathrm{CH}_{3} \mathrm{COCH}_{3} \\
& \mathrm{CH}_{3} \mathrm{COCH} \mathrm{CH}_{3}->\mathrm{CH}_{3} \mathrm{CO}+\mathrm{CH}_{3} \\
& \mathrm{CH}_{3} \mathrm{CO}->\mathrm{CH}_{3}+\mathrm{CO}
\end{aligned}
$$

$$
\begin{aligned}
& k_{e}=7 \times 10^{8} \sec ^{-1} \\
& k_{f}=? 3 \times 10^{10} \sec ^{-1} \\
& k_{c}=40 \sec ^{-1} \\
& k_{d}=? 4 \times 10^{10} \sec ^{-1}
\end{aligned}
$$

For a net overall reaction of:

$$
\left(\mathrm{CH}_{3}\right)_{3} \mathrm{COOC}\left(\mathrm{CH}_{3}\right)_{3}-\rightarrow 4 \cdot \mathrm{CH}_{3}+2 \mathrm{CO}
$$

Thus, by varying the [TBH]:[TBP] ratio, we can vary the $[\mathrm{OH}]:\left[\mathrm{CH}_{3}\right]$ ratio, and by monitoring $[\mathrm{OH}]$ by our usual procedure and comparing the observed $[\mathrm{OH}]$ decay plots with the results of computer simulations, the rate coefficient for $\mathrm{OH}+\mathrm{CH}_{3}$ could be extracted.

Several factors contribute to the total uncertainty in the rate coefficient determination. The scatter in measured rate coefficients is typically about $10 \%$, slightly more than the uncertainty in the determination of the exponential decay rate of an individual absorption profile. Our calibration factor, $v$, has a $10 \%$ uncertainty. Other sources of error include uncertainties in the concentration of the RH reagent in the mixtures (2\%), the initial pressure (1\%), the shock-compressed density ratio ( $0.35 \%)$, the oscilloscope time-sweep calibration (2\%), and the approximate nature of relating absorption decay to concentration decay (4\%). The $0.3 \%$ uncertainty in the shock velocity determinatin translates into a $6.5 \mathrm{~K}$ temperature uncertainty. Considering these sources of uncertainty, we calculate the total RMS uncertainty in the rate coefficients to be about $15 \%$, and the uncertainty in the temperature to be about $15 \mathrm{~K}$. 


\section{PROGRESS}

To date we have completed and published $6,7,8$ shock tube measurements of the reactions of $\mathrm{OH}$ radicals with several species: $\mathrm{H}_{2}, \mathrm{CH}_{4}, \mathrm{C}_{2} \mathrm{H}_{6}, \mathrm{C}_{3} \mathrm{H}_{8}, c-\mathrm{C}_{5} \mathrm{H}_{10}, i-\mathrm{C}_{4} \mathrm{H}_{10}, i-\mathrm{C}_{8} \mathrm{H}_{18}$, neo- $\mathrm{C}_{8} \mathrm{H}_{18}, 2,3$-dimethylbutane, $\mathrm{C}_{2} \mathrm{H}_{2}, \mathrm{C}_{2} \mathrm{H}_{4}, \mathrm{C}_{3} \mathrm{H}_{6}, \mathrm{HCHO}, \mathrm{CH}_{3} \mathrm{COCH}_{3}, \mathrm{CH}_{3} \mathrm{OH}$, and $\mathrm{C}_{2} \mathrm{H}_{5} \mathrm{OH}$. The results, all near $1200 \mathrm{~K}$ and $1 \mathrm{~atm}$, are summarized in Table I.

\begin{tabular}{|c|c|}
\hline Reagent & $\underline{\text { Rate Coefficient }\left(10^{9} \mathrm{~L} / \mathrm{mol}-\mathrm{s}\right)}$ \\
\hline $\mathrm{H}_{2}$ & 2.7 \\
\hline $\mathrm{CH}_{4}$ & 2.6 \\
\hline $\mathrm{C}_{2} \mathrm{H}_{6}$ & 9.0 \\
\hline $\mathrm{C}_{3} \mathrm{H}_{8}$ & 16.0 \\
\hline$i-\mathrm{C}_{4} \mathrm{H}_{10}$ & 12.6 \\
\hline$c-\mathrm{C}_{5} \mathrm{H}_{10}$ & 28.0 \\
\hline$n e o-\mathrm{C}_{8} \mathrm{H}_{18}$ & 18.0 \\
\hline$i-\mathrm{C}_{8} \mathrm{H}_{18}$ & 22.0 \\
\hline 2,3-dimethylbutane & 21.0 \\
\hline $\mathrm{C}_{2} \mathrm{H}_{2}$ & 0.28 \\
\hline $\mathrm{C}_{2} \mathrm{H}_{4}$ & 2.6 \\
\hline $\mathrm{C}_{3} \mathrm{H}_{6}$ & 9.6 \\
\hline $\mathrm{HCHO}$ & 12.0 \\
\hline $\mathrm{CH}_{3} \mathrm{COCH}_{3}$ & 5.3 \\
\hline $\mathrm{CH}_{3} \mathrm{OH}$ & 5.2 \\
\hline $\mathrm{C}_{2} \mathrm{H}_{5} \mathrm{OH}$ & 5.3 \\
\hline
\end{tabular}

In addition, in a separate set of experiments, the reaction rate of $\mathrm{OH}$ with $\mathrm{CH}_{3}$ radicals was measured. ${ }^{9}$ This process is always occuring in our system because $\mathrm{CH}_{3}$ radicals are produced in the decompositien of the TBH (See Section II above). Extraction of the $\mathrm{OH}+\mathrm{CH}_{3}$ reaction rate coefficient of $1.1 \times 10^{11} \mathrm{~L} \mathrm{~mol}^{-1} \mathrm{~s}^{-1}$ required the utilization of a detailed computer model. Although we did not directly measure the products of the reaction, we believe that the primary mechanism for $\mathrm{OH}$ removal of $\mathrm{CH}_{3}$ near $1200 \mathrm{~K}$ and 1 atm is by their combination to form $\mathrm{CH}_{3} \mathrm{OH}$.

The work on the hydrocarbons provided the incentive for revising an earlier model ${ }^{10}$ used to carry out thermochemical kinetics/transition state theory (TK-TST) calculations for the reaction rate coefficients of $\mathrm{OH}$ with alkanes. In a careful review of the application of TK-TST to OH + alkane reactions we concluded that there are good theoretical reasons for expecting different primary, secondary, or tertiary $\mathrm{H}$ atoms (distinguished on the basis of number of nearest neighboring $\mathrm{C}$ atoms) to have different rate parameters. If true, this invalidates the usual procedure of treating the total rate coefficient for $\mathrm{OH}+\mathrm{RH} \mathrm{H}$ abstraction processes as the sum of invariant primary, secondary, and tertiary rates multiplied by the respective number of such $\mathrm{H}$ atoms in the molecule. A separate question is whether there is really sufficient experimental evidence to justify distinguishing among different types of primary (or secondary, or tertiary) $\mathrm{H}$ atoms, or whether, given experimental and theoretical uncertainties, it is adequate to trcat them all as equivalent. We have concluded that there are 


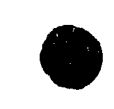

measurable and unambiguous differences among various primary $\mathrm{H}$ atom abstractions, and possibly among secondary atoms, but the database cannot as yet distinguish among tertiary $\mathrm{H}$ atoms. ${ }^{11}$

In order to obtain the maximum benefit from experimental data and the TK-TST calculations, it is necessary to know equilibrium constants for the abstraction reactions. This requires thermochemical parameters for various alkyl radicals, which are not generally available. In order to generate our own equilibrium constant data, we made an extensive examination of methods for the estimation of enthalpies, entropies, and heat capacities for alkanes and alkyl radicals. This study resulted in two publications, one focusing on the alkanes $^{12}$ and the other, on the alkyl radicals themselves. ${ }^{13}$ 


\section{•}

\section{PUBLICATIONS RELATED TO THIS GRANT}

J. F. Bott and N. Cohen, "A Shock Tube Study of the Reaction of the Hydroxyl Radical with $\mathrm{H}_{2}, \mathrm{CH}_{4}$, c- $\mathrm{C}_{5} \mathrm{H}_{10}$, and $\mathrm{i}-\mathrm{C}_{4} \mathrm{H}_{10}$," Int. J. Chem. Kinetics 21, 485 (1989).

N. Cohen, "Predicting the Preexponential Temperature Dependence of Bimolecular Metathesis Reaction Rate Coefficients using Transition State Theory," Int. J. Chem. Kinetics 21, 909 (1989).

N. Cohen, "Revised Group Additivity Values of Enthalpies for Linear Alkanes and Alkyl Radicals," Aerospace Corp. Report ATR-88(7073)-2 (15 June 1988).

N. Cohen, "Are Reaction Rate Coefficients Additive? Revised Transition State Theory Calculations for OH + Alkane Reactions," Int. J. Chem Kinetics 23, 397 (1991).

N. Cohen, "The Use of Trarisition-State Theory to Extrapolate Rate Coefficients for Reactions of $\mathrm{H}$ Atoms with Alkanes," Int. J. Chem. Kinetics 23, 683 (1991).

J. F. Bott and N. Cohen, "A Shock Tube Study of the Reaction of Methyl Radicals with Hydroxyl Radical," Int. J. Chem. Kinetics 23, 1017 (1991).

J. F. Bott and N. Cohen, "A Shock Tube Study of the Reactions of the Hydroxyl Radical with Several Combustion Species," Int. J. Chem. Kinetics 23, 1075 (1991).

N. Cohen and S. W. Benson, "The Thermochemistry of Alkanes and Cycloalkanes," Chapter 6 in The Chemistry of Alkanes and Cycloalkanes, R. Patai and Z. Rappoport, eds. (Wiley, 1992), pp. 215-287.

N. Cohen, "The Thermochemistry of Alkyl Free Radicals," ATR-91(7189)-1 (15 July 1991); accepted for publication in J. Phys. Chem. 


\section{REFERENCES}

1. S. W. Benson, Thermochemical Kinetics, 2nd edn. (Wiley, 1976) and references cited therein.

2. J. F. Bott, J. Chem. Phys. 57, 96 (1972).

3. G. L. Schott and R. W. Getzinger, in Physical Chemistry of Fast Reactions, P. B. Levitt, ed. (London: Plenum Press, 1973), p. 81.

4. J. Ernst, H. Gg. Wagner, and R. Zellner, Ber. Bunsenges. Phys. Chem. 81, 1270 (1977).

5. J. N., Bradley, W. D. Capey, R. W. Fair, and D. K. Pritchard, Int. J. Chem. Kinet. 8, 549 (1976).

6. J. F. Bott and N. Cohen, Int. J. Chem. Kinet. 16, 1557 (1984).

7. J. F. Bott and N. Cohen, Int. J. Chem. Kinet. 21, 485 (1989).

8. J. F. Bott and N. Cohen, Int. J. Chem. Kinet. 23, 1075 (1991).

9. J. F. Bott and N. Cohen, Int. J. Chem. Kinet. 23, 1017 (1991).

10. N. Cohen, Int. J. Chem. Kinet. 14, 1339 (1982); 15, 503 (1983).

11. N. Cohen, Int. J. Chem. Kinet. 23, 397 (1991).

12. N. Cohen and S. W. Benson, "The Thermochemistry of Alkanes and Cycloalkanes," in The Chemistry of Alkanes and Cycloalkanes, R. Patai and Z. Rappoport, eds. (Wiley, 1992), pp. 215-287.

13. N. Cohen, "The Thermochemistry of Alkyl Free Radicals," ATR-91(7189)-1 (15 July 1991); accepted for publication in J. Phys. Chem. 

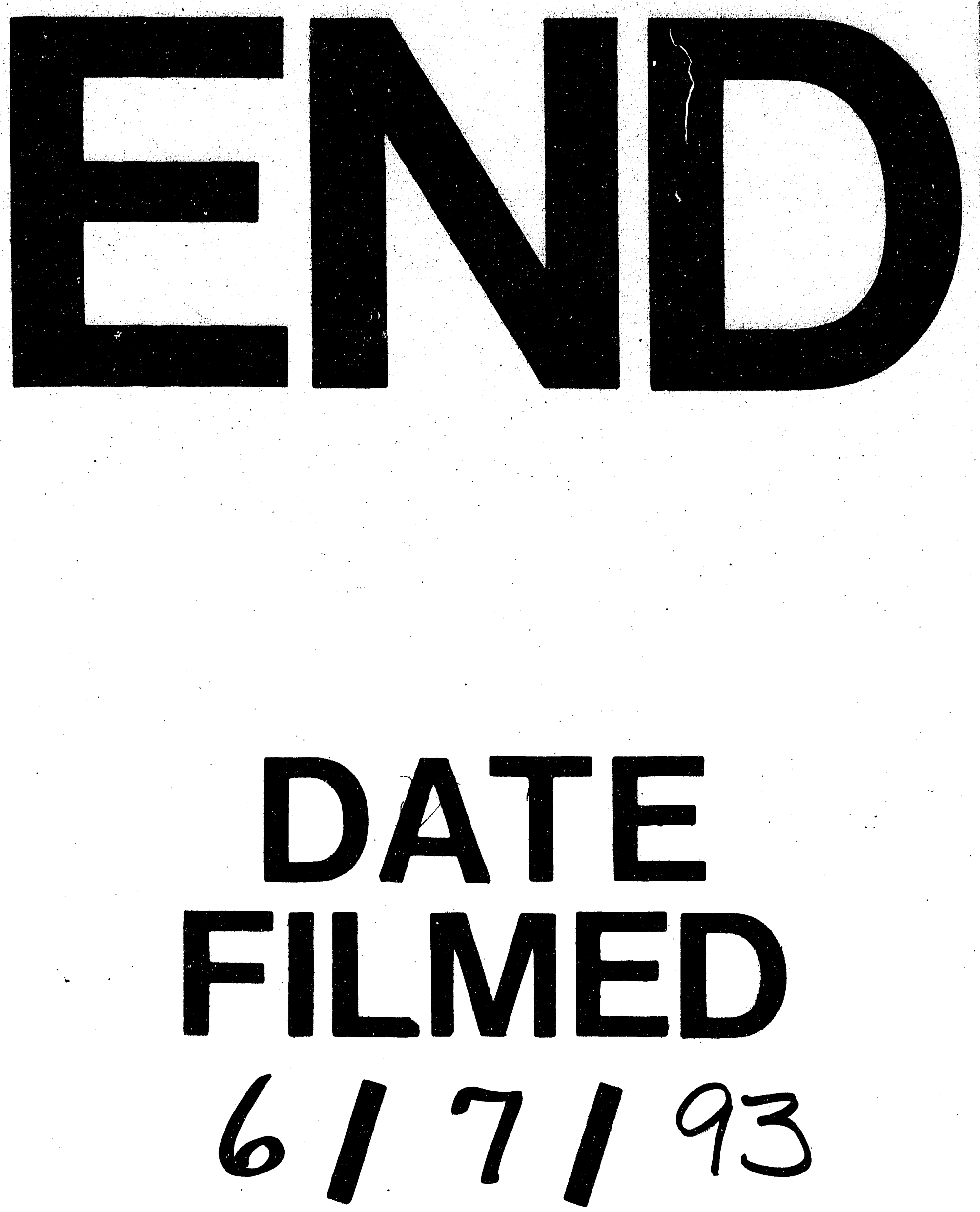

1 
